\title{
Safety/tolerability of the anti-semaphorin 4D antibody VX15/2503 in a randomized phase 1 trial
}

\section{OPEN}

Christopher LaGanke, MD

Lawrence Samkoff, MD Keith Edwards, MD Lily Jung Henson, MD Pavle Repovic, MD Sharon Lynch, MD Lael Stone, MD David Mattson, MD Aaron Galluzzi, MSc Terrence L. Fisher, PhD Christine Reilly, BS Laurie A. Winter, BS John E. Leonard, PhD Maurice Zauderer, $\mathrm{PhD}$

Correspondence to Dr. Leonard: jleonard@vaccinex.com

Supplemental data at Neurology.org/nn

\section{ABSTRACT}

Objective: To evaluate the safety, tolerability, pharmacokinetics (PK), and pharmacodynamics (PD) of VX15/2503 in a randomized, single-dose, dose-escalation, double-blind, placebo-controlled study enrolling adult patients with MS.

Methods: Single IV doses of VX15/2503 or placebo were administered. Ten patients each were randomized (4:1 randomization ratio) into 5 ascending dose cohorts of 1, 3, 6, 10, or $20 \mathrm{mg} / \mathrm{kg}$. Safety, immunogenicity, PK/PD, MRI, ECG, and lymphocyte subset levels were evaluated. A Dose Escalation Safety Committee (DESC) approved each dose escalation.

Results: VX15/2503 was well tolerated, and all participants completed the study. Antibody treatment-related adverse events were primarily grade 1 or 2 and included urinary tract infection (12.5\%) and muscle weakness, contusion, and insomnia (each 7.5\%). No dose-limiting toxicities were observed, and no maximum tolerated dose was determined. One subject $(20 \mathrm{mg} / \mathrm{kg}$ ) experienced disease relapse 3 months before study entry and exhibited a grade 3 (nonserious) increase in brain lesions by day 29, possibly related to VX15/2503. Twenty-nine patients exhibited human anti-humanized antibody responses; 5 with titer $\geq 100$. No anti-VX15/2503 antibody responses were fully neutralizing. VX15/2503 $\mathrm{C}_{\max }$, area under the time-concentration curve, and mean half-life increased with dose level; at $20 \mathrm{mg} / \mathrm{kg}$, the $T_{1 / 2}$ was 20 days. Cellular SEMA4D saturation occurred at serum antibody concentrations $\leq 0.3 \mu \mathrm{g} / \mathrm{mL}$, resulting in decreased cSEMA4D expression. At $20 \mathrm{mg} / \mathrm{kg}$, cSEMA4D saturation persisted for $\geq 155$ days. Total sSEMA4D levels increased with dose level and declined with antibody clearance.

Conclusions: These results support the continued investigation of VX15/2503 in neurodegenerative diseases.

\section{ClinicalTrials.gov identifier: NCT01764737.}

Classification of evidence: This study provides Class III evidence that anti-semaphorin 4D antibody VX15/2503 at various doses was safe and well tolerated vs placebo, although an increase in treatment-emergent adverse events in the treatment group could not be excluded (risk difference $-0.7 \%, 95 \% \mathrm{Cl}-28.0 \%$ to $32.7 \%$ ). Neurol Neuroimmunol Neuroinflamm 2017;4:e367; doi: 10.1212/NXI.0000000000000367

\section{GLOSSARY}

$\mathbf{A E}=$ adverse event; $\mathbf{A U C}=$ area under the time-concentration curve; $\mathbf{B B B}=$ blood-brain barrier; $\mathbf{C T C A E}=$ Common Terminology Criteria for Adverse Event; C-SSRS = Columbia-Suicide Severity Rating Scale; EAE = experimental autoimmune encephalomyelitis; DESC = Dose Escalation Safety Committee; DLT = dose-limiting toxicity; EDSS = Expanded Disability Status Scale; EOI = end of infusion; $\mathbf{G d}=$ gadolinium; HAHA = human anti-human antibody; $\mathbf{M T D}=$ maximum tolerated dose; $\mathbf{O P C}=$ oligodendrocyte precursor cell; $\mathbf{P D}=$ pharmacodynamics; $\mathbf{P K}=$ pharmacokinetics; $\mathbf{Q T c}=\mathrm{QT}$ interval; $\mathrm{SAE}=$ serious adverse event; TEAE $=$ treatment-emergent adverse event.

Semaphorins are a family of soluble and transmembrane proteins serving as axonal-guidance factors and other functions in the development and regeneration of the CNS. ${ }^{1}$ They also participate in vascular growth, tumor progression, and the activation and migration of immune and inflammatory precursor cells.

Author affiliations are provided at the end of the article.

Funding information and disclosures are provided at the end of the article. Go to Neurology.org/nn for full disclosure forms. The Article Processing Charge was funded by Vaccinex, Inc.

Coinvestigators are listed at Neurology.org/nn.

This is an open access article distributed under the terms of the Creative Commons Attribution-NonCommercial-NoDerivatives License 4.0 (CC BY-NC-ND), which permits downloading and sharing the work provided it is properly cited. The work cannot be changed in any way or used commercially without permission from the journal. 
Semaphorin 4D (SEMA4D) is a $300-\mathrm{kDa}$ transmembrane protein predominantly expressed on $\mathrm{T}$ cells, but also expressed on monocytes, professional antigen-presenting cells, platelets, and oligodendrocytes. ${ }^{2}$ Cellular activation stimulates increased expression of cSEMA4D. In addition, the extracellular domain of cSEMA4D can be proteolytically cleaved from the cell surface yielding a 240 $\mathrm{kDa}$, homodimeric soluble form of the protein (sSEMA4D) ${ }^{3}$; both forms are biologically active. ${ }^{4}$ Finally, although SEMA4D functions primarily as a ligand, it may also function as a receptor, signaling through its cytoplasmic domain. $^{5}$

Three cellular receptors have been identified for SEMA4D. Plexin-B1 (PLXNB1), a high-affinity receptor, is expressed on dendritic and endothelial cells, oligodendrocytes, astrocytes, and neurons. ${ }^{6}$ SEMA4D engagement with PLXNB1 induces activation and migration of endothelial cells; it also induces growth cone collapse in neurons, apoptosis of neural precursor cells, and process extension collapse and apoptosis of oligodendrocytes. ${ }^{7-9}$ Plexin-B2 (PLXNB2), a SEMA4C receptor expressed on keratinocytes, has intermediate affinity for SEMA4D but can activate SEMA4D-positive $\gamma \delta \mathrm{T}$ cells aiding epithelial repair. ${ }^{10}$ Finally, CD72 is a low-affinity SEMA4D receptor that influences B-lymphocyte maturation. ${ }^{11}$

MS is a chronic neuroinflammatory disease characterized by blood-brain barrier (BBB) breakdown, localized myelin destruction, and progressive neuronal degeneration. SEMA4D-induced signaling cascades induce glial activation, neuronal process collapse, inhibit migration and differentiation of oligodendrocyte precursor cells (OPCs), and disrupt endothelial tight junctions forming the BBB. Because SEMA4D mediates both inflammatory responses and demyelination, ${ }^{12}$ it is a potential target for treatment of neurodegenerative diseases. ${ }^{6}$ The murine antiSEMA4D antibody MAb 67-2 blocks SEMA4D binding to OPC in vitro and reduces semaphorin-mediated apoptosis ${ }^{13}$; it also promotes OPC migration to the site of lesions, repairs lysolecithin-induced demyelination in vivo, and attenuates experimental autoimmune encephalomyelitis in multiple rodent models. ${ }^{13}$

VX15/2503, a high-affinity humanized monoclonal anti-SEMA4D antibody derived from MAb 67-2, blocks the interaction between SEMA4D and its three receptors. ${ }^{13-}$ ${ }^{16}$ This article describes the results of a phase 1 study evaluating the safety and tolerability of VX15/2503 in patients with MS; no similar trials have been described. We conducted this study to evaluate VX15/2503 as a potential therapeutic agent for MS and, possibly, other neurodegenerative diseases.

METHODS Study drug. VX15/2503 was produced by Catalent Pharma Solutions (Madison, WI) and vialed by Ajinomoto Althea, Inc. (San Diego, CA) ${ }^{14,16}$; generic and proprietary names have not been assigned. A matched placebo was supplied for comparison of safety observations (see appendix e-1 at Neurology.org/nn).

Study design. This phase 1 study was a single-dose, doseescalation, randomized, double-blind, placebo-controlled trial enrolling adult patients diagnosed with relapsing or progressive MS for at least 1 year as defined by the McDonald criteria. ${ }^{17}$ The primary protocol-specified objective was to determine the safety and tolerability of VX15/2503 in patients with MS; secondary and exploratory objectives were to characterize the single-dose pharmacokinetics (PK), pharmacodynamics (PD), and immunogenicity of VX15/2503 (see appendix e-1). No interim analysis was planned, and no changes were made to study objectives or trial design after study initiation.

The study was conducted at 11 US clinical centers. Each of the 5 dose cohorts included 10 patients; ascending dose levels of $1,3,6,15$, and $20 \mathrm{mg} / \mathrm{kg}$ were used based on results of completed toxicology and clinical studies. ${ }^{14,16}$ Enrolled participants were randomly assigned (4:1 randomization ratio, drug to placebo) on study day 1 to receive a single IV dose of either VX15/ 2503 or placebo; each cohort contained 8 antibody-treated patients. The randomization schedule was software generated; patient treatment assignments were communicated using an interactive voice response system. This system also prescribed, for each patient, specific numbered vials of investigational agent.

Vital signs were measured before, during, and after study drug infusion. Intracohort patient dosing was staggered by at least 24 hours after the first 4 patients in the prior cohort had been dosed; study drug administration to the remaining patients in a cohort was staggered by at least 2 hours between patients. No more than 3 patients were infused in any 1-day period; all patients were monitored for 24 hours after dosing. On study day 2, serum chemistry, hematology, $\mathrm{PK} / \mathrm{PD}$, and lymphocyte enumeration samples, among others, were obtained from each subject. Participants also received an in-person or telephonic clinical assessment on day 4. Safety follow-up periods of 6 weeks (cohort 1 ), 8 weeks (cohorts 2 and 3), 12 weeks (cohort 4), or 27 weeks (cohort 5), based on expected durations of cSEMA4D saturation, were specified for collection of comprehensive safety, PK, and PD samples.

Escalation to the next dose cohort proceeded only after the DESC (consisting of three independent neurologists with clinical expertise in MS, the sponsor's representatives, and the study medical monitor) determined by data review that the previous 
dose level was safe and well tolerated. Cohort data reviews were blinded and included adverse events (AEs), ECGs, vital signs, and clinical laboratory and lymphocyte subset results through day 15 , and human anti-humanized antibody (HAHA) ${ }^{18}$ and PK/PD data; the committee made no requests for review of unblinded data.

Stopping rules. The infusion for any patient was to be stopped if the patient experienced a possibly drug-related serious $\mathrm{AE}$ (SAE) or a possibly drug-related significant non-serious $\mathrm{AE}$ which, in the opinion of the principal investigator, study medical monitor, or sponsor's medical representative, warranted discontinuation of the study for that patient. The occurrence of any of the following drug-related safety events also warranted DESC evaluation and possible subject discontinuation: one or more SAEs; a severe $\mathrm{AE}$ or an elevation in a protocol-specified liver enzyme occurring in $\geq 2$ participants at the same dose level; or an increase in corrected QT interval (QTc) of 60 milliseconds over baseline on 2 consecutive days or any QTc $>500$ milliseconds in $\geq 2$ patients in the same dose cohort (see appendix e- 1 for additional details).

Standard protocol approval, registrations, and patient consents. Institutional review board approvals for the study protocol, amendments, and informed consent documents were obtained before use in the study; written informed consent was obtained from study participants before the initiation of study procedures. This study was conducted in accordance with the Declaration of Helsinki, International Conference on Harmonization $(\mathrm{ICH})$ guidelines, and applicable portions of the United States Code of Federal Regulations. The ClinicalTrials.gov identifier (NCT01764737) was obtained before study initiation.

Study participants. Men or women 18-60 years of age previously diagnosed with MS for at least 1 year as defined by the McDonald criteria, and who had an Expanded Disability Status Scale (EDSS) score of 0-6.5, inclusive, at screening were eligible for enrollment if they met the following criteria: a body mass index of $18-32 \mathrm{~kg} / \mathrm{m}^{2}$, inclusive; willingness to undergo and had no contraindications to brain MRI; willingness to use a medically acceptable method of contraception throughout the study period and for 6 months after the dose of study drug, unless patient was surgically sterile or postmenopausal. Before study drug administration, male patients had to agree to defer from donating sperm for 6 months, and women of childbearing potential were required to have a negative serum pregnancy test at screening (confirmed via baseline urinalysis). Finally, participants on stable treatment regimens of interferon $\beta$, glatiramer acetate, or dalfampridine were allowed to enroll.

Exclusionary criteria were an MS relapse that did not stabilize within 30 days before the start of screening; any clinically significant cardiac, endocrine, hematologic, hepatic, immunologic, metabolic, urologic/gynecologic, pulmonary, neurologic, psychiatric, or renal conditions; a history of relevant clinically significant allergic or anaphylactic reactions; any other clinically significant major disease that, as assessed by the investigator, could have posed a risk to patient safety or interfered with the study evaluations, procedures, or completion; any clinically significant laboratory value outside the normal range at screening; or abnormal hematologic, renal, or hepatic function based on laboratory tests.

Pregnant or breastfeeding women were excluded. Patients who had received treatment with any MS disease-modifying therapy other than interferon $\beta$ or glatiramer acetate within 3 months before dosing were also excluded, as were subjects who had received natalizumab, daclizumab, or fingolimod for any indication within 6 months before dosing, or had any prior treatment with alemtuzumab, rituximab, mitoxantrone, total lymphoid irradiation, bone marrow transplantation, or $\mathrm{T}$ cell or $\mathrm{T}$-cell receptor vaccination. Patients were also excluded if they had received any experimental agent within 6 months before dosing, or within a period equivalent to 5 half-lives of the agent (whichever was longer); or were currently involved in any other research study, or had undergone any major surgical procedure within 4 weeks before dosing. Participants were also excluded if they had a history of congestive heart failure, symptomatic ischemia, conduction abnormalities uncontrolled by conventional intervention, or myocardial infarction within 6 months before dosing, or had a clinically significant ECG finding at screening, as determined by the investigator. Finally, patients with sensitivity to VX15/ 2503 or its excipients, with a known or suspected HIV or hepatitis B or hepatitis $\mathrm{C}$ infection, or with a known or suspected allergy to gadolinium $(\mathrm{Gd})$ or other contraindications to brain MRI were excluded.

Safety assessments. In addition to determining the safety and tolerability of VX15/2503 in patients with MS, we also characterized the single-dose PK, PD, and immunogenicity of VX15/ 2503. Safety assessments included AEs and SAEs; immunogenicity (Ig levels; HAHA); enumeration of T/B lymphocytes and natural killer cells; clinical laboratory evaluations (hematology, coagulation parameters, serum chemistry, and urinalysis); vital signs; 12-lead ECGs; physical examination findings; and Columbia-Suicide Severity Rating Scale (C-SSRS); these assessments were used in the determination of an maximum tolerated dose (MTD) by the DESC (see appendix e-1 for additional information).

AE severity was rated according to the Common Terminology Criteria for Adverse Events (CTCAE) version 4.03; AEs that were possibly or probably related to the study drug and were ongoing at the time a patient completed the study or discontinued early were followed until resolution or until stabilized. All treatment-emergent AEs were reported to the Food and Drug Administration.

PK/PD assays. Blood samples were collected at screening, predose, after the end of infusion (EOI), and on days 1, 2, and 4 and then periodically thereafter; PK/PD samples were analyzed as described. ${ }^{16}$ No CSF samples were collected for analysis. PK parameters were estimated for the $\mathrm{PK}$ population using noncompartmental analyses. Standard $\mathrm{PK}$ parameters $\left(\mathrm{C}_{\max } ; \mathrm{C}_{\mathrm{L}}\right.$; $\mathrm{T}_{\max }$; and effective half-life, etc.) were determined by cohort and time point. Analyses of area under the time-concentration curve (AUC) and $\mathrm{C}_{\max }$ to assess dose proportionality were performed as described. ${ }^{19}$ PD evaluations for peripheral blood T-cell cSEMA4D expression and saturation levels as well as for serum sSEMA4D levels were performed as described, ${ }^{16,20}$ using samples collected at PK time points (see supplemental materials). As VX15/2503 half-life increased with dose level, final cSEMA4D saturation samples were collected on day 43 (cohort 1), day 57 (cohorts 2 and 3), and day 85 (cohorts 4 and 5), respectively; cohort 5 subjects showing persistent cSEMA4D saturation had additional samples collected on days 155 and 190 for analysis, as necessary.

Statistical analysis. Because the primary objective of this study was assessment of the safety and tolerability of VX15/2503, statistical analyses of typical efficacy variables were not performed. Results from the PK population were used for summary statistics and determination of mean serum VX15/2503 concentrations. Descriptive statistics (number of patients, mean, SD, percent coefficient of variation, median, minimum, maximum, and the 25 th and 75 th percentiles) were used to summarize the serum 


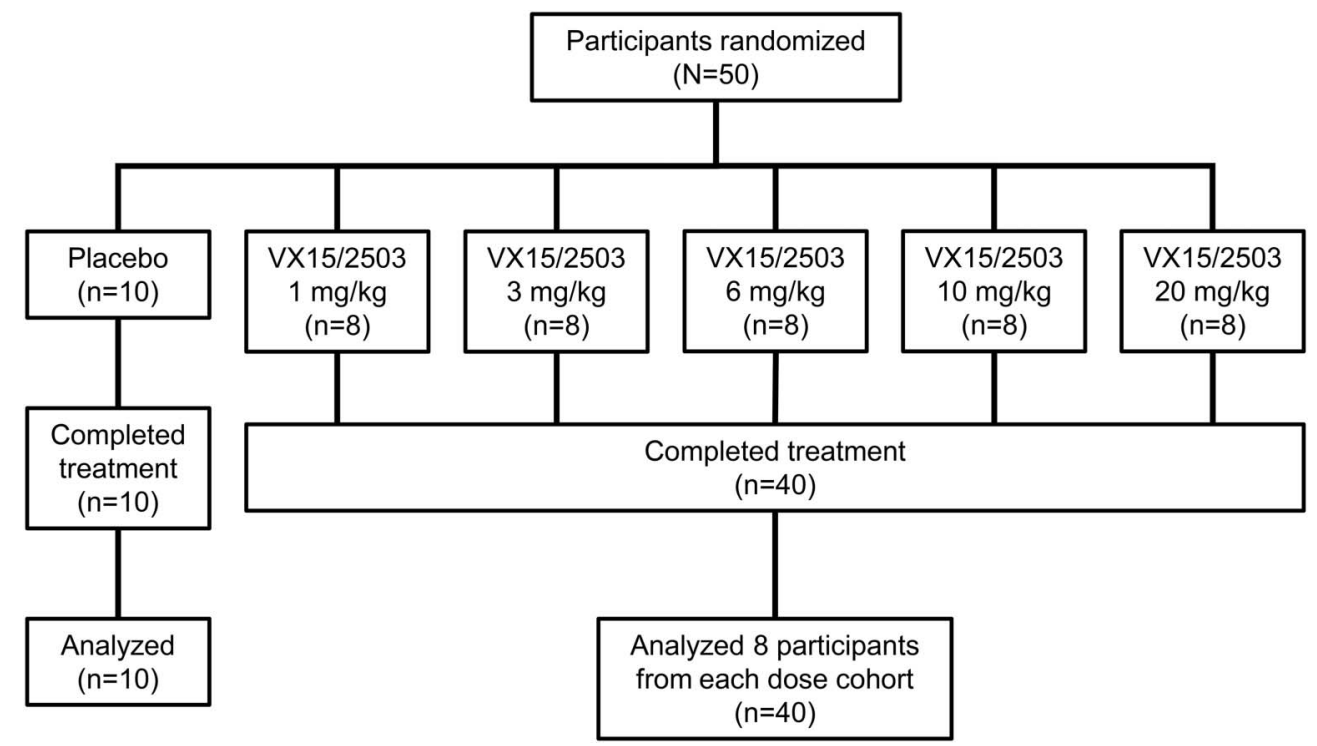

This flow diagram depicts the disposition of the participants in this single-dose, dose-escalation study of intravenously administered VX15/2503. Forty participants were treated with VX15/2503 and 10 with placebo; none discontinued the study. The median infusion time for all patients was 60 minutes, with durations ranging from 45 to 170 minutes.

concentrations at each scheduled time point by treatment. Geometric mean values were presented for $\mathrm{C}_{\max }, \mathrm{C}_{\mathrm{L}}$, and $\mathrm{AUC}$ values.

Disease activity assessments. Biological activity was assessed in an exploratory manner using brain MRI and EDSS data. ${ }^{21}$ EDSS measurements were performed at baseline, on day 29 and at time points specified for PK assessments. Brain scans were performed at baseline and study day 29 with and without Gd; all MRIs were centrally analyzed and evaluated for the number of Gd-enhancing lesions, the number of new and existing unenhancing T1 lesions, the number of new and enlarging T2 lesions, and total volume of $\mathrm{T} 1$ and $\mathrm{T} 2$ lesions (see appendix e-1).

RESULTS Demographics and participant disposition. Fifty patients were enrolled and randomized (figure 1); the sample size was not based on statistical considerations. Baseline characteristics were similar between treatment and placebo groups (see tables $1 \mathrm{~S}$ and $2 \mathrm{~S}$; appendix e-1). Twenty-nine (58\%) of the subjects were women and $44(88 \%)$ were Caucasian; 5 patients (10\%) were African American. The median participant age was 48 years (range 22-60); the median time since MS diagnosis for the study population overall was 12.0 years (range 2-40 years). Forty-seven patients (94\%) had received prior MS therapy. The mean EDSS score at baseline for the treated population $(\mathrm{n}=40)$ was $3.8(\mathrm{SD}=2.0)$ vs an EDSS of $5.1(\mathrm{SD}=1.7)$ for the placebo population $(\mathrm{n}=10)$. The first participant was enrolled on November 29, 2012, and the last subject's final visit was on November 14, 2014. There were no early terminations or discontinuations; all participants were analyzed in the safety and exploratory populations.
Each patient received one infusion. The mean body weight at screening for the treated population $(\mathrm{n}=40)$ was $77.7 \mathrm{~kg}$ (range $51.7-115 \mathrm{~kg}$ ); the mean total dose administered was $617.9 \mathrm{mg}$ (range 50.0$1,940 \mathrm{mg}$ ). Serum sample analysis indicated that no placebo patients received active drug. Dose escalation

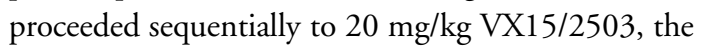
highest planned dose level; no dose-limiting toxicities were observed, and no MTD was determined.

Safety assessments. Treatment-emergent adverse events (TEAEs) were reported for 26 of 40 (65\%) VX15/ 2503-treated patients (table 1); no dose-dependent pattern was evident in TEAE incidence. TEAEs for 18 of 26 antibody-treated patients (69.2\%) and for 7 of 10 placebo-treated patients were considered unrelated to treatment. Treatment-related TEAEs were noted for $8(20 \%)$ antibody-treated patients and 3 placebo patients; no participants experienced a TEAE leading to a fatal outcome, early termination, or discontinuation. TEAEs most commonly reported by VX15/2503-treated patients were for urinary tract infections (5 patients; $12.5 \%$ ), and muscular weakness, contusion, and insomnia (3 subjects each; 7.5\%). Three subjects (7.5\%) experienced grade 3 TEAEs after VX15/2503 infusion, and 23 participants $(57.5 \%)$ experienced grade 1 or 2 events. The severe TEAEs included one SAE (foot fracture requiring hospitalization and surgery; $3 \mathrm{mg} / \mathrm{kg}$; unrelated); fatigue (1 patient; $6 \mathrm{mg} / \mathrm{kg}$; nonserious; unrelated); and CNS lesion (1 patient; $20 \mathrm{mg} / \mathrm{kg}$; nonserious; possibly related). The latter participant experienced a grade 3 increase from baseline to day 29 
Table 1 Summary of treatment-emergent AEs for the safety population after a single dose of VX15/2503 or placebo

\begin{tabular}{|c|c|c|c|c|c|c|c|c|}
\hline AEs, N (\%) & Placebo (N = 10) & \multicolumn{6}{|c|}{$\mathrm{VX15} / 2503, \mathrm{mg} / \mathrm{kg}$} & Total $(\mathrm{N}=50)$ \\
\hline Patients reporting $\mathrm{AE}$ & $4(40.0)$ & 7 (87.5) & 5 (62.5) & 3 (37.5) & $4(50.0)$ & 7 (87.5) & $26(65.0)$ & $30(60.0)$ \\
\hline Patients reporting TEAE & $4(40.0)$ & 7 (87.5) & $5(62.5)$ & $3(37.5)$ & $4(50.0)$ & 7 (87.5) & $26(65.0)$ & $30(60.0)$ \\
\hline Patients with treatment-related TEAE ${ }^{a}$ & $2(20.0)$ & $2(25.0)$ & $0(0.0)$ & $1(12.5)$ & $1(12.5)$ & $4(50.0)$ & $8(20.0)$ & $10(20.0)$ \\
\hline Patients with serious TEAE ${ }^{b}$ & $0(0.0)$ & $0(0.0)$ & 1 (12.5) & $0(0.0)$ & $0(0.0)$ & $0(0.0)$ & $1(2.5)$ & $1(2.0)$ \\
\hline \multicolumn{9}{|l|}{ Most frequent TEAE ${ }^{d}$} \\
\hline Urinary tract infection & $0(0.0)$ & 1 (12.5) & 2 (25.0) & $0(0.0)$ & $1(12.5)$ & 1 (12.5) & 5 (12.5) & 5 (10.0) \\
\hline Muscular weakness & $0(0.0)$ & 3 (37.5) & $0(0.0)$ & $0(0.0)$ & $0(0.0)$ & $0(0.0)$ & $3(7.5)$ & $3(6.0)$ \\
\hline Upper respiratory tract infection & $0(0.0)$ & $0(0.0)$ & 1 (12.5) & $1(12.5)$ & $0(0.0)$ & $0(0.0)$ & $2(5.0)$ & $2(4.0)$ \\
\hline Fatigue & $0(0.0)$ & $0(0.0)$ & $0(0.0)$ & $1(12.5)$ & $0(0.0)$ & 1 (12.5) & $2(5.0)$ & $2(4.0)$ \\
\hline Headache & $1(10.0)$ & $0(0.0)$ & $0(0.0)$ & 1 (12.5) & $0(0.0)$ & $1(12.5)^{e}$ & $2(5.0)$ & $3(6.0)$ \\
\hline Rash & $0(0.0)$ & $0(0.0)$ & $0(0.0)$ & $0(0.0)$ & $0(0.0)$ & $2(25.0)$ & $2(5.0)$ & $2(4.0)$ \\
\hline Fall & $1(10.0)$ & $0(0.0)$ & $0(0.0)$ & $0(0.0)$ & $1(12.5)$ & 1 (12.5) & $2(5.0)$ & $3(6.0)$ \\
\hline
\end{tabular}

Abbreviations: AE = adverse event; CTCAE, Common Terminology Criteria for Adverse Events; Gd, gadolinium; TEAE = treatment-emergent adverse event.

A summary of the AEs arising after a single dose of VX15/2503 or placebo. Each dose cohort contained ten randomized patients, 8 of whom were treated with VX15/2503.

${ }^{\text {a }}$ Possibly, probably, or definitely related to study treatment; CTCAE version 4.0.

${ }^{\mathrm{b}}$ Foot fracture resulting from automobile accident requiring hospitalization and surgical repair; unrelated to study treatment.

${ }^{c}$ Grade 3 increase in Gd-enhancing lesions; baseline to day 29; nonserious; possibly related to study treatment.

${ }^{\mathrm{d}}$ Reported for incidence $\geq 5 \%$ of VX15/2503-treated participants; TEAEs were grade 1 or 2 .

e Grade 3; unrelated.

of the number of T1 Gd-enhancing lesions from 11 to 27 , and an increase in the EDSS score from 3.5 to 4.0. Although the lesion increase was considered possibly related to VX15/2503 treatment, this patient experienced a relapse 3 months before study entry and exhibited active disease at screening.

In general, there were no clinically important changes in physical examination findings, vital signs, serum chemistry, hematology, coagulation parameters, or urinalysis values after administration of VX15/2503. Similarly, C-SSRS results revealed no suicidal ideation, regardless of the dose level. No changes in ECG results occurred that suggested a possible treatment effect. Central evaluation of ECG results noted transient, clinically nonsignificant shifts from normal to abnormal for 3 of 40 patients $(7.5 \%)$ treated at 3,6 , or $10 \mathrm{mg} / \mathrm{kg}$ dose level of VX15/2503; no dose correlation was apparent, and no similar shifts were noted for placebotreated patients. Last, flow cytometric analyses of lymphocytes and lymphocyte subsets showed no obvious trends in changes in the levels of these various populations after VX15/2503 administration, regardless of the dose.

Immunogenicity. HAHA responses were confirmed beginning on day 8 for 25 of 40 VX15/2503treated patients $(62.5 \%)$, and on day 15 , or later, for another 4 patients. Five of these 29 patients (17.2\%) (cohorts 1-3) exhibited HAHA responses requiring serum dilutions of $\geq 100$; the remainder exhibited low-titer responses. One of these 5 patients (cohort 2) exhibited a T-cell SEMA4D saturation value of $2 \%$ on day 43 , vs $88-95 \%$ for the 7 other cohort 2 patients, possibly reflecting a delayed HAHA (neutralizing) response. Cellular SEMA4D desaturation occurred on day 57 for the remaining antibody-treated cohort 2 participants. No other HAHA-positive patients exhibited similar effects on cSEMA4D saturation.

TEAEs reported on day 1 possibly reflective of infusion-related reactions included 1 placebo-treated patient (mild dizziness/flushing and mild hyperhidrosis; possibly related) and 4 VX15/2503-treated 

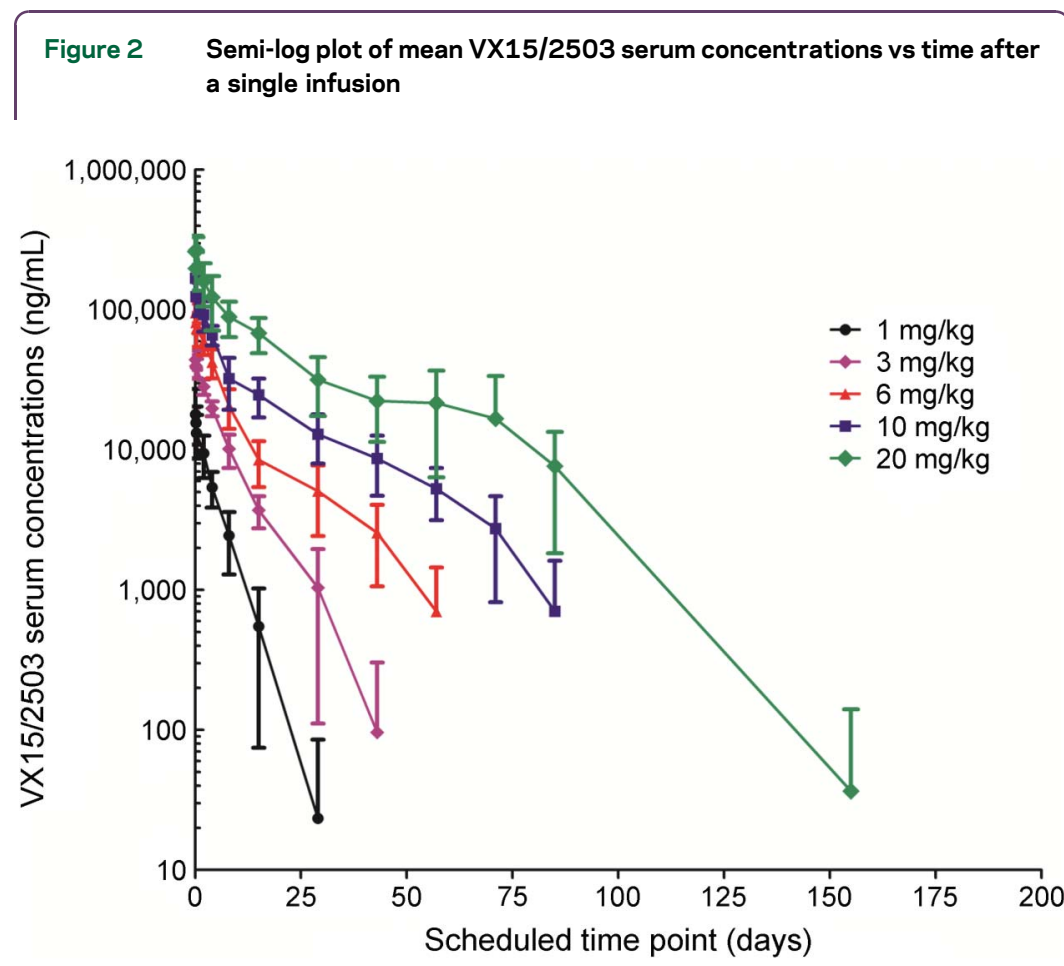

Mean serum VX15/2503 concentrations are shown vs scheduled sampling days. Data shown are for antibody-treated patients in each of the 5 dose cohorts; samples from placebo-treated subjects were assayed but not reported because of the absence of antibody in these samples. Sampling times were end of infusion, 4 and 8 hours on days $12,4,8$, $15,29,43,57,71,85,155$, and 190; time points beyond day 29 were successively applied to cohorts 2 through 5 . Data shown represent mean values \pm SD. Serum assays were performed in triplicate using a validated method. ${ }^{15,16}$

patients; 1 each in cohort 1 (mild nausea; probably related; low-titer response) and cohort 4 (moderate blood pressure elevation 1 hour after infusion; unrelated; low titer), and 2 VX15/2503-treated (low-titer) patients in cohort 5 (subject 1: mild headache and mild rash; both unrelated, and subject 2: moderate myalgia; unrelated).

PK and PD. Serum antibody concentration data derived from analysis of samples from the 40 VX15/2503-treated patients are shown in figure 2; target-mediated disposition appears evident at lower serum antibody concentrations. Mean half-life and $\mathrm{C}_{\max }$ values (table 2 ) increased linearly with increasing dose level, ranging from roughly 4 days at $1 \mathrm{mg} / \mathrm{kg}$ VX15/2503 to approximately 20 days at $20 \mathrm{mg} / \mathrm{kg}$; $\mathrm{AUC}_{0-\infty}$ values, however, increased at a rate greater than proportional to the dose.

VX15/2503 serum concentrations of $\leq 0.3$ $\mu \mathrm{g} / \mathrm{mL}$, attained with single doses of VX15/2503 $\geq$ $1.0 \mathrm{mg} / \mathrm{kg}$, produced complete T-cell SEMA4D saturation; cSEMA4D desaturation occurred with VX15/2503 clearance from the periphery (figure 3). The mean cSEMA4D saturation value at the EOI for all 5 dose levels was $88.0 \%$ (range 68.5\%-98.7\%). Cellular SEMA4D saturation fell with antibody clearance and reached approximately $20 \%$ saturation at roughly 30 days after infusion at the $1 \mathrm{mg} / \mathrm{kg}$ dose level. With the increasing VX15/2503 dose level, longer periods of cSEMA4D saturation were observed, with $\geq 155$ days required after infusion for full cSEMA4D desaturation for patients treated with $20 \mathrm{mg} / \mathrm{kg}$ VX15/2503. Mean saturation values for samples collected from placebo-treated participants ranged from zero to $13 \%$ (median $0.5 \%$; not shown). Cellular SEMA4D expression levels decreased to approximately 50\% after VX15/2503 binding to the cell surface receptor and its internalization and returned to baseline expression levels after antibody clearance, as described previously. ${ }^{16}$

Levels of total sSEMA4D (free and antibody bound) in the sera of antibody-treated patients increased with VX15/2503 dose level and peaked at roughly day 30 (not shown) primarily because of complexed sSEMA4D (see appendix e-1). Soluble SEMA4D levels returned to baseline after antibody clearance; mean sSEMA4D levels reached to baseline by day 43 for the $1 \mathrm{mg} / \mathrm{kg}$ dose cohort and day 155 for the $20 \mathrm{mg} / \mathrm{kg}$ dose cohort. Placebo-treated patients showed no similar PD effects.

MS disease activity. Although efficacy was not formally evaluated, EDSS assessments at day 29 remained essentially unchanged compared with baseline following single doses of VX15/2503 from 1 to $20 \mathrm{mg} / \mathrm{kg}$. Similarly, no effects on MS disease activity were evident based on brain MRI results (appendix e-1 and table 3S).

DISCUSSION Single IV infusions of VX15/2503 were well tolerated by the patients with MS enrolled in this study. The highest planned dose of $20 \mathrm{mg} / \mathrm{kg}$ was evaluated, and no MTD was determined. Analysis of the VX15/2503-treated population for TEAE incidence and severity revealed no safety trends. No clinically meaningful changes were reported for physical examination, laboratory parameters, or C-SSRS results for antibody-treated patients. Although 29 VX15/2503-treated patients developed HAHA responses, most were low-titer responses and none exhibited fully neutralizing antibodies.

Pharmacologic effects were similar to those reported previously for VX15/2503. ${ }^{14,16}$ Lymphocyte levels generally remained unchanged from baseline, regardless of the antibody dose level. The threshold for cSEMA4D saturation of human T cells was $\leq 0.3$ $\mu \mathrm{g} / \mathrm{mL}$, as previously reported. ${ }^{16}$ Furthermore, as observed previously, expression of cSEMA4D on peripheral blood $\mathrm{T}$ lymphocytes declined for all VX15/2503-treated patients because of receptor internalization and returned to baseline levels after antibody clearance. ${ }^{16}$ Also, serum levels of total sSEMA4D increased with the dose level consistent 


\begin{tabular}{|c|c|c|c|c|c|}
\hline \multirow{2}{*}{$\begin{array}{l}\text { Table } 2 \text { PK pe } \\
\text { Parameter }\end{array}$} & neters derived from & compartmental anal & of VX15/2503 PK pc & ation data & \\
\hline & \multicolumn{5}{|c|}{ VX15/2503 dose level, mg/kg } \\
\hline \multicolumn{6}{|l|}{$A U C_{0-\infty}, h \cdot n g / m L$} \\
\hline $\mathbf{n}$ & 7 & 8 & 8 & 8 & 8 \\
\hline Geometric mean & $1,437,307.3$ & $5,844,994.6$ & $13,838,405.9$ & $31,146,683.8$ & $83,803,601.7$ \\
\hline Median & $1,677,427.6$ & $5,669,043.0$ & $14,292,817.0$ & $32,527,928.8$ & $83,058,364.6$ \\
\hline \multicolumn{6}{|l|}{$C_{\max }, n g / m L$} \\
\hline $\mathrm{n}$ & 8 & 8 & 8 & 8 & 8 \\
\hline \multicolumn{6}{|l|}{$T_{\max }, h$} \\
\hline $\mathbf{n}$ & 8 & 8 & 8 & 8 & 8 \\
\hline Mean (SD) & $5.1(8.25)$ & 3.7 (3.49) & 2.2 (3.03) & $1.7(1.32)$ & $5.2(4.05)$ \\
\hline Geometric mean & 2.4 & 2.5 & 1.5 & 1.4 & 3.5 \\
\hline Median & 1.2 & 1.6 & 1.1 & 1.3 & 5.5 \\
\hline \multicolumn{6}{|l|}{$t_{1 / 2}, d$} \\
\hline n & 7 & 8 & 8 & 8 & 8 \\
\hline Mean (SD) & $3.7(1.61)$ & $6.1(1.87)$ & $10.1(2.68)$ & $14.9(5.95)$ & $20.0(4.82)$ \\
\hline Geometric mean & 49.9 & 37.1 & 33.3 & 22.4 & 19.0 \\
\hline Median & 50.2 & 38.3 & 32.2 & 23.0 & 18.2 \\
\hline
\end{tabular}

Abbreviations: $\mathrm{AUC}_{\mathrm{O}-\infty}=$ area under the concentration-time curve extrapolated to infinity; $\mathrm{CL}=$ clearance; $\mathrm{C}_{\max }=$ maximum serum concentration; $\mathrm{t}_{1 / 2}=$ antibody half-life; $\mathrm{PK}$ = pharmacokinetics; $\mathrm{T}_{\max }=$ time of maximum serum concentration.

A summary of the PK parameters determined after a single IV administration of VX15/2503. Summary statistics for each PK parameter were determined for each dose level. Geometric mean values were presented for $C_{\max }, C L$, and AUC values. Analyses of AUCs and $C_{\max }$ to assess dose proportionality for VX15/2503 were performed using a power model. ${ }^{20}$

No subjects randomized to receive placebo were treated with the study drug.

Half-life in days is derived from the data for half-life in hours by dividing the values by 24 .

with the increased half-life of the VX15/2503sSEMA4D complex vs those of the soluble ligand; these levels also declined after antibody clearance. . $^{15,16,22}$

A semi-log plot of serum antibody concentration vs time suggested that VX15/2503 clearance was primarily due to target-mediated disposition (figure 2), as is commonly observed for monoclonal antibodies targeting cellular ligands. ${ }^{14}$ The effective half-life increased linearly from approximately 4 days at 1 $\mathrm{mg} / \mathrm{kg}$ to roughly 20 days at $20 \mathrm{mg} / \mathrm{kg} \mathrm{VX} 15 / 2503$; $\mathrm{C}_{\max }$ values also increased linearly over this dose range. $\mathrm{AUC}_{0-168}$ values, however, exhibited a slightly greater than dose proportional increase with the increasing dose level.
The findings from this study suggested that VX15/2503 was well tolerated by this patient population. Use of this anti-SEMA4D antibody represents a potential therapeutic strategy for subjects with neurodegenerative disease. Nonclinical studies indicate that this approach may promote survival, differentiation, and migration of OPCs, all negatively affected by SEMA4D, potentially promoting remyelination of damaged neurons. ${ }^{13}$ The possible clinical benefits of VX15/2503 will be evaluated in future studies enrolling patients with MS.

Anti-SEMA4D treatment may also reverse damage to the $\mathrm{BBB},{ }^{13}$ and nonclinical studies using the YAC-128 mouse model of Huntington disease ${ }^{2}$ 
Figure 3 Mean percent cellular SEMA4D saturation vs time after VX15/2503 administration

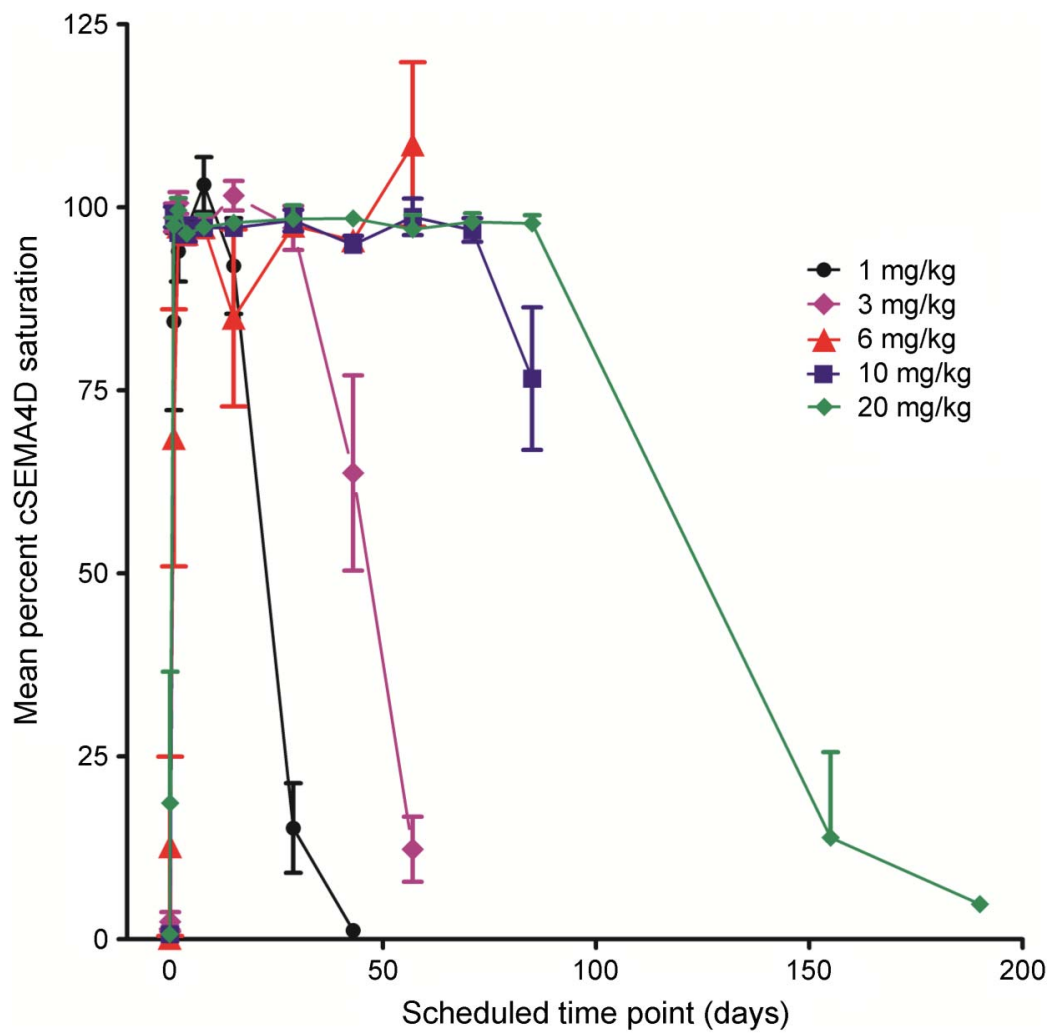

Percent VX15/2503 saturation of cSEMA4D on peripheral T lymphocytes is shown for antibody-treated participants in each dose cohort. The scheduled sampling times for each dose cohort were as described in the legend of figure 2 . Data shown represent mean values $\pm \mathrm{SE}$; flow cytometric assays were performed in triplicate and data analyzed as previously described. ${ }^{16,20} \mathrm{~T}$-cell saturation values below $20 \%$ were considered unsaturated; mean predose saturation values ranged between $0.7 \%$ and $18 \%$.

suggest that repeated anti-SEMA4D treatment slows brain volume loss in these mice vs sham-treated animals. ${ }^{2}$ Finally, anti-SEMA4D treatment may reverse glial cell and astrocyte activation. ${ }^{2,6,13}$ Based on these results and those presented here, we initiated a phase 2 clinical study evaluating VX15/2503 in patients with prodromal and early-manifest Huntington disease (NCT02481674).

\section{AUTHOR AFFILIATIONS}

From the North Central Neurology Associates (C.L.), Cullman, AL; University of Rochester Medical Center (L.S.), NY; MS Center of Northeastern New York (K.E.), Latham; Piedmont Healthcare (L.J.H.), Atlanta, GA; Swedish Neuroscience Institute-MS Center (P.R.), Seattle, WA; University of Kansas Medical Center (S.L.), MO; Cleveland Clinic (L.S.), OH; Indiana University Medical Center (D.M.), Indianapolis; PRA Health Sciences (A.G.), Lenexa, KS; and Vaccinex, Inc. (T.L.F., C.R., L.A.W. J.E.L., M.Z.), Rochester, NY.

\section{AUTHOR CONTRIBUTIONS}

Dr. Leonard wrote the draft manuscript and participated in its revision. Dr. Fisher, Dr. Leonard, and Dr. Zauderer made substantive intellectual contributions to the design and conceptualization of this study; participated in the analysis and interpretation of the data; and revised the manuscript. Dr. LaGanke, Dr. Samkoff, Dr. Edwards, Dr. Henson, Dr. Repovic, Dr. Lynch, Dr. Stone, and Dr. Mattson provided study participants and participated in data acquisition and study coordination. Mr. Galluzzi performed the statistical analyses. Mrs. Reilly and Ms. Winter participated in data acquisition and the review and revision of the manuscript. All authors exercised editorial control of the content of the manuscript and approved the final version. Vaccinex, Inc. provided financial support for conduct of the study, data acquisition and analysis, and the writing of the manuscript.

\section{STUDY FUNDING}

This phase 1 study was funded solely by Vaccinex, Inc. Vaccinex, Inc., a private Delaware corporation, has patent rights based on inventions described in this publication and is developing a humanized antiSEMA4D antibody for clinical use. Dr. Fisher, Dr. Zauderer, and Dr. Leonard, and Mrs. Reilly are employees of or have ownership interest in Vaccinex, Inc. Ms. Winter was a Vaccinex employee at the time she participated in data acquisition.

\section{DISCLOSURE}

C. Laganke reports no disclosures. L. Samkoff received publishing royalties from John Wiley \& Sons. K. Edwards received travel funding and/or speaker honoraria from Biogen, Genzyme, and Novartis; is employed by MS Center of Northeastern NY; has consulted for Biogen, Genzyme, EMD Serono, and Novartis; served on the speaker's bureau for Biogen and Genzyme; and received research support from Actelion, Biogen, Envivo, Eisai Inc, Genentech, Genzyme, Hoffmann-La Roche, Novartis, Pfizer, and Vaccinex. L.J. Henson served on the scientific advisory board for Genzyme; received travel funding and speaker honoraria from Genzyme; was employed by Piedmont, Swedish Health Services; consulted for BioMarin and Mitsubishi Tanabe; served on the speaker's bureau for Genzyme, Novartis, Teva, Pfizer, and Serono; received research support from Genzyme, Biogen, Novartis and Opexa; her spouse received research support from Parexel; holds stock in Merck and Amgen; and served as an expert witness. P. Repovic consulted for and served on the speaker's bureau for Biogen, Sanofi Genzyme, Teva, EMD Serono, and Novartis; also consulted for Anvil Biosciences; served on the speaker's Bureau for Pfizer and Acorda; and received research support from Novartis, NIH, and The Guthy-Jackson Charitable Foundation. S. Lynch received speaker honoraria from MS-Cure; received research support from Novartis, Alexion, Acorda, Actelion, Biogen, Sanofi, Roche, Genentech, Chugai, MedImmune, Vaccinex, Sun Pharma, Teva, Genyzme, MedDay, Opexa, NIH, and National Multiple Sclerosis Society. L. Stone is editor-in-chief for International Journal of MS Care and received research support from National Multiple Sclerosis Society. D. Mattson served on the scientific advisory board for Acorda and Biogen; received travel funding and/or speaker honoraria from Teva, Biogen, EMD Serono, Pfizer, Acorda, Novartis, Genzyme, Bayer, and Questcorp; served on the speaker's Bureau for Teva, Biogen, EMD Serono, Pfizer, Acorda, Novartis, Genzyme, Bayer, and Questcor; received research support from Teva, Biogen, MedImmune, Roche, ONO, Acorda, Genentech, Novartis, Genzyme, Sanofi-Aventis, Actelion, Vaccinex, Alkermes, and Indiana Clinical Translational Science Institute/NIH. A. Galluzzi has been employed by Premier Research, Chiltern International, and PRA Health Sciences. T.L. Fisher is employed by and holds stock or stock options in Vaccinex, Inc. C. Reilly has been employed by Vaccinex Inc. L. A. Winter has been employed by Vaccinex and Ortho Clinical Diagnostics. J.E. Leonard holds patents for Therapeutic application of chimeric antibody to human lymphocyte restricted differentiation antigen for treatment of B Cell lymphoma, Therapeutic application of chimeric and radiolabeled antibodies to human B lymphocyte restricted differentiation antigen for treatment of B cell lymphoma, and Chimeric antiCD20 antibody, expression and use of anti-CD20 antibodies as in vitro or in vivo purging agents in patients receiving bone marrow transplantation or peripheral blood stem cell transplant; is Senior Vice President, Development; and holds stock/stock options in Vaccinex. M. Zauderer holds a patent for Use of anti-semaphorin 4D antibody to treat cancer and Use of anti-semaphorin 4D antibody to treat neuroinflammatory/ neurodegenerative diseases; has been employed by and holds stock or stock options in Vaccinex, Inc. Go to Neurology.org/nn for full disclosure forms.

Received November 8, 2016. Accepted in final form April 28, 2017. 


\section{REFERENCES}

1. Hota P, Buck M. Plexin structures are coming: opportunities for multilevel investigations of semaphorin guidance receptors, their cell signaling mechanisms, and functions. Cell Mol Life Sci 2012;69:3765-3805.

2. Southwell AL, Franciosi S, Villanueva EB, et al. Antisemaphorin 4D immunotherapy ameliorates neuropathology and some cognitive impairment in the YAC128 mouse model of Huntington disease. Neuro Biol Dis 2015;76:46-56.

3. Suzuki K, Kumanogoh A, Kikutani H. Semaphorins and their receptors in immune cell interactions. Nat Immunol 2008;9:17-23.

4. Zhu L, Bergmeier W, Wu J, et al. Regulated surface expression and shedding support a dual role for semaphorin $4 \mathrm{D}$ in platelet responses to vascular injury. Proc Natl Acad Sci USA 2007;104:1621-1626.

5. Hall KT, Boumsell L, Schultze JL, et al. Human CD100, a novel leukocyte semaphorin that promotes B-cell aggregation and differentiation. Proc Natl Acad Sci USA 1996; 93:11780-11785.

6. Okuno T, Nakatsuji Y, Moriya M, et al. Roles of Sema4D-plexin-B1 interactions in the central nervous system for pathogenesis of experimental autoimmune encephalomyelitis. J Immunol 2010;184:1499-1506.

7. Giordano S, Corso S, Conrotto P, et al. The semaphorin $4 \mathrm{D}$ receptor controls invasive growth by coupling with Met. Nat Cell Biol 2002;4:720-724.

8. Basile JR, Gavard J, Gutkind JS. Plexin-B1 utilizes RHOA and $\mathrm{ROK}$ to promote the integrin-dependent activation of AKT and ERK, and endothelial cell motility. J Biol Chem 2007;282:34888-34895.

9. Giraudon P, Vincent P, Vuaillat C, et al. Semaphorin CD100 from activated $\mathrm{T}$ lymphocytes induces process extension collapse in oligodendrocytes and death of immature neural cells. J Immunol 2004;172:1246-1255.

10. Witherden DA, Watanabe M, Garijo O, et al. The CD100 receptor interacts with its plexin B2 ligand to regulate epidermal gammadelta $\mathrm{T}$ cell function. Immunity 2012;37:314-325.

11. Kumanogoh A, Watanabe C, Lee I, et al. Identification of CD72 as a lymphocyte receptor for the class IV semaphorin CD100: a novel mechanism for regulating B cell signaling. Immunity 2000;13:621-631.

12. Kumanogoh A, Kikutani H. The CD100-CD72 interaction: a novel mechanism of immune regulation. Trends Immunol 2001;22:670-676.

13. Smith E, Jonason A, Reilly C, et al. SEMA4D compromises blood-brain barrier, activated microglia, and inhibits remylenation in neurodegenerative disease. Neuro Biol Dis 2015;73:254-268.

14. Leonard JE, Fisher TE, Winter L, et al. Nonclinical safety evaluation of VX15/2503: a humanized IgG4 antiSEMA4D antibody. Mol Can Therap 2015;14:964-972.

15. Fisher TL, Reilly CA, Winter LA, et al. Generation and preclinical characterization of an antibody specific for SEMA4D. MAbs 2016;8:150-162.

16. Patnaik A, Weiss GJ, Leonard JE, et al. Safety, pharmacokinetics and pharmacodynamics of a humanized antisemaphorin 4D antibody, in a first-in-human study of patients with advanced solid tumors. Clin Cancer Res 2015;22:827-836.

17. Polman $\mathrm{CH}$, Reingold SC, Banwell B, et al. Diagnostic criteria for multiple sclerosis: 2010 revisions to the McDonald criteria. Ann Neurol 2011;69:292-302.

18. Bourdage J, Cook C, Farrington DL, Chain JS, Konrad RJ. An affinity capture elution (ACE) assay for detection of anti-drug antibody to monoclonal antibody therapeutics in the presence of high levels of drug. J Immunol Methods 2007;327:10-17.

19. Smith BP, Vandenhende FR, DeSante KA, et al. Confidence interval criteria for assessment of dose proportionality. Pharm Res 2000;17:1278-1283.

20. Fisher TL, Seils J, Reilly C, et al. Saturation monitoring of VX15/2503, a novel semaphorin 4D-specific antibody, in clinical trials. Cytometry B Clin Cytom 2016;90: 199-208.

21. Kurtzke JF. Rating neurologic impairment in multiple sclerosis: an expanded disability status scale (EDSS). Neurology 1983;33:1444-1452.

22. Gordon MS, Margolin K, Talpaz M, et al. Phase 1 safety and pharmacokinetic study of recombinant human antivascular endothelial growth factor in patients with advanced cancer. J Clin Oncol 2001;19:843-850. 


\title{
Neurology ${ }^{\oplus}$ \\ Neuroimmunology \& Neuroinflammation
}

\author{
Safety/tolerability of the anti-semaphorin 4D antibody VX15/2503 in a randomized \\ phase 1 trial \\ Christopher LaGanke, Lawrence Samkoff, Keith Edwards, et al. \\ Neurol Neuroimmunol Neuroinflamm 2017;4; \\ DOI 10.1212/NXI.0000000000000367
}

This information is current as of June 16, 2017

Neurol Neuroimmunol Neuroinflamm is an official journal of the American Academy of Neurology.

Published since April 2014, it is an open-access, online-only, continuous publication journal. Copyright

Copyright $\odot 2017$ The Author(s). Published by Wolters Kluwer Health, Inc. on behalf of the American

Academy of Neurology. All rights reserved. Online ISSN: 2332-7812.

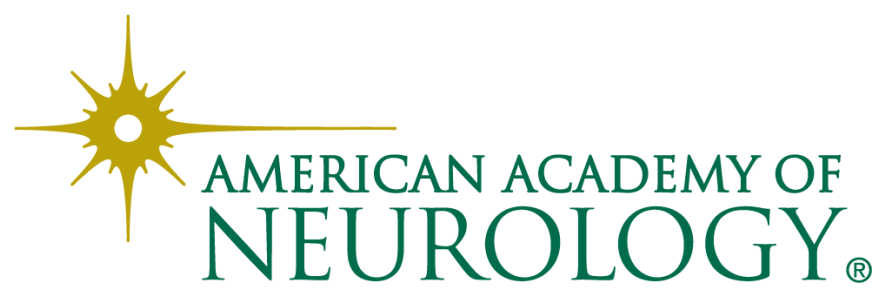




\section{Updated Information \& Services}

\section{Supplementary Material}

\section{References}

Citations

Subspecialty Collections

\section{Permissions \& Licensing}

\section{Reprints}

including high resolution figures, can be found at: http://nn.neurology.org/content/4/4/e367.full.html

Supplementary material can be found at: http://nn.neurology.org/content/suppl/2017/06/28/4.4.e367.DC1 http://nn.neurology.org/content/suppl/2017/06/28/4.4.e367.DC2

This article cites 22 articles, 6 of which you can access for free at: http://nn.neurology.org/content/4/4/e367.full.html\#\#ref-list-1

This article has been cited by 1 HighWire-hosted articles: http://nn.neurology.org/content/4/4/e367.full.html\#\#otherarticles

This article, along with others on similar topics, appears in the following collection(s):

\section{Autoimmune diseases}

http://nn.neurology.org//cgi/collection/autoimmune_diseases

\section{Class III}

http://nn.neurology.org//cgi/collection/class_iii

Clinical trials Randomized controlled (CŌNSORT agreement) http://nn.neurology.org//cgi/collection/clinical_trials_randomized_cont rolled_consort_agreement

\section{MRI}

http://nn.neurology.org//cgi/collection/mri

Multiple sclerosis

http://nn.neurology.org//cgi/collection/multiple_sclerosis

Information about reproducing this article in parts (figures,tables) or in its entirety can be found online at:

http://nn.neurology.org/misc/about.xhtml\#permissions

Information about ordering reprints can be found online: http://nn.neurology.org/misc/addir.xhtml\#reprintsus

Neurol Neuroimmunol Neuroinflamm is an official journal of the American Academy of Neurology.

Published since April 2014, it is an open-access, online-only, continuous publication journal. Copyright Copyright $\odot 2017$ The Author(s). Published by Wolters Kluwer Health, Inc. on behalf of the American Academy of Neurology. All rights reserved. Online ISSN: 2332-7812.

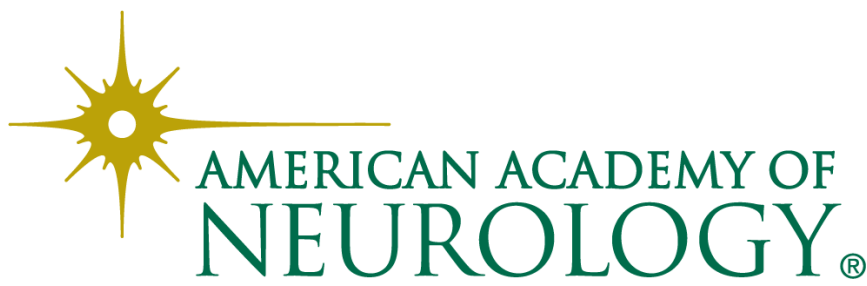

